\title{
Autologous fat grafting in the treatment of velopharyngeal insufficiency: Clinical outcomes and treatment tolerability survey in a case series of 21 patients
}

\author{
Renzo Panizza, Marco Ghiglione, Enrico Maria Zingarelli, Michela Massa, Claudio Carlini ${ }^{1}$, \\ Rossella Arnoldi ${ }^{1}$, Alessio Pini Prato ${ }^{1}$, Silvia Scarrone ${ }^{2}$, Francesco Vaccarella ${ }^{1}$ \\ Departments of Plastic and Reconstructive Surgery, ${ }^{1}$ Pediatric Surgery and ${ }^{2}$ Operating Theatre Management, SS. Antonio e \\ Biagio e Cesare Arrigo Hospital, Alessandria, Italy
}

Address for correspondence: Dr. Enrico Maria Zingarelli, Department of Plastic and Reconstructive Surgery, SS. Antonio e Biagio e Cesare Arrigo Hospital, Via Venezia 16, 15121, Alessandria, Italy. E-mail: enrico.zingarelli@gmail.com

\section{ABSTRACT}

Introduction: Velopharyngeal insufficiency (VPI) is the inability to close the velopharyngeal sphincter during phonation and/or feeding. VPI is clinically characterised by hypernasal speech and nasal regurgitation. In cases of severe VPI, pharyngoplasty is recommended. Cases of mild-to-moderate VPI can be treated with fat grafting of the posterior pharyngeal wall in addition to speech therapy. The lipofilling can also be useful after pharyngoplasty to improve the outcomes.Materials and Methods: Twenty-one patients (14 males and 7 females), ages 4-23 affected by mild-to-moderate VPI and treated with lipofilling were included in this retrospective study. The mean injected fat volume was $7.95 \mathrm{cc}$ (median $6 \mathrm{cc}$, min $4 \mathrm{cc}$, max $20 \mathrm{cc}$ and range $16 \mathrm{cc}$ ). The follow-up ranged from 6 to 60 months. The pre- and post-operative Borel-Maisonny scores were compared using Wilcoxon test. Moreover, we performed a telephone survey with the aim to assess the parental perception on child's speech and quality of life after the surgical treatment. Results: Despite the small sample size, in this case series, we observed a statistically significant Borel-Maisonny score improvement and a parental satisfaction rate of about $85 \%$. Conclusions: The augmentation of the posterior pharyngeal wall in addition to speech therapy improved the Borel-Maisonny score and the intelligibility of this case series of patients affected by mild-to-moderate VPI. In these patients, evaluated in a multidisciplinary approach, this technique allowed us to avoid major surgical procedures that would modify the anatomy of the velopharyngeal port. However, prospective comparative studies or randomised controlled trials could be useful to compare fat grafting with velopharyngoplasty techniques, with the aim to clarify indications and to define a specific treatment protocol.

\section{KEY WORDS:}

Lipofilling; posterior pharyngeal wall augmentation; velopharyngeal insufficiency

\begin{tabular}{|l|l|}
\hline \multicolumn{2}{|c|}{ Access this article online } \\
\hline Quick Response Code: & Website: \\
\hline & www.ijps.org \\
\cline { 2 - 2 } & DOI: \\
\hline
\end{tabular}

This is an open access journal, and articles are distributed under the terms of the Creative Commons Attribution-NonCommercial-ShareAlike 4.0 License, which allows others to remix, tweak, and build upon the work non-commercially, as long as appropriate credit is given and the new creations are licensed under the identical terms.

For reprints contact: reprints@medknow.com

How to cite this article: Panizza R, Ghiglione M, Zingarelli EM, Massa M, Carlini C, Arnoldi R, et al. Autologous fat grafting in the treatment of velopharyngeal insufficiency: Clinical outcomes and treatment tolerability survey in a case series of 21 patients. Indian J Plast Surg 2018;51:145-54. 


\section{INTRODUCTION}

elopharyngeal insufficiency (VPI) is the inability to close the velopharyngeal sphincter during phonation and/or feeding that can be a consequence of an enlarged velopharyngeal gap and a diminished muscular contraction of the velum and posterolateral pharyngeal walls. ${ }^{[1]}$ The causes of VPI can be either congenital or iatrogenic. Moreover, VPI can be linked to over 400 recognised syndromes ${ }^{[2]}$ and a correct pre-operative diagnosis is mandatory in terms of a proper clinical orientation. The most common causes of VPI are cleft palate, submucous cleft, velar hypoplasia, velar paralysis or paresis, after coma paralysis, velar hemiparesis, VPI post-adenoidectomy and the outcomes of velar resection for cancer.

The first-line treatment is speech therapy, but in cases of insufficient improvement, surgery may be indicated. Different surgical strategies are described in the literature: sphincter pharyngoplasty, palatal pushback, velopharyngoplasty (VPP) with posterior pharyngeal flap and pharyngeal posteriorwall augmentation with different kind of fillers. In recent years, the autologous fat grafting has been proposed, and in the last 20 years, different studies have been published, with the aim to clarify the role of this technique that, in selected patients, allows to improve voice resonance and reduces nasal air escape without modifying the anatomy of the velopharyngeal port. Furthermore, this surgical approach can be used to improve the outcomes after major surgery. Despite its simplicity, that allows to perform multiple procedures in the same patient, it is of a paramount importance not to forget the potentially severe complications described in the literature. Therefore, a multidisciplinary approach is mandatory in VPI assessment and management.

\section{MATERIALS AND METHODS}

A total of 21 patients were involved in this retrospective study (14 males and 7 females), ages 4-23 (mean 9, 43 years, median 7 years and range 19 years) affected by mild-to-moderate velopharyngeal insufficiency and treated with the augmentation of the posterior pharyngeal wall with autologous fat injection between May 2012 and December 2016, in the Department of Plastic and Reconstructive Surgery of the Hospital SS. Antonio e Biagio e Cesare Arrigo of Alessandria, Italy. All the patients were evaluated with a multidisciplinary approach. After a period of at least 1 year of speech therapy, the patients were operated by an experienced team composed of plastic surgeons of the Department of Plastic and Reconstructive Surgery and paediatric surgeons of the Department of Pediatric Surgery of the Hospital SS. Antonio e Biagio e Cesare Arrigo of Alessandria (Italy). Written informed consent was obtained from adult patients and from both parents in children patients. The pre- and post-operative assessment included clinical examination, phoniatrician evaluation and nasofibroscopy. The follow-up ranged from 6 to 60 months.

\section{Inclusion criteria}

The inclusion criteria were as follows:

- Clinical evidence of mild-to-moderate hypernasal speech (Borel-Maisonny score 1/2, 2/1 2b, 2 m 2/3)

- Velar mobility allowing a velopharyngeal closure of at least $50 \%$

- Long-term speech therapy (at least 1 year).

\section{Exclusion criteria}

The following criteria were excluded from this study:

- Contraindication to general anaesthesia

- Severe articulatory defect and bad intelligibility (Borel-Maisonny score: 3)

- Severe cognitive deficiency.

The aetiology was primary VPI for 11 patients, secondary VPI after surgical correction of cleft palate for 9 patients ( 1 patient was affected by Pierre Robin syndrome),VPIafteradenotonsillectomyforadenotonsillar hypertrophy for 1 patient (affected by Down syndrome). One patient had a previous pharyngoplasty. One patient had a pharyngoplasty 14 months later.

Patient's details are reported in Table 1.

\section{Patient selection and pre- and post-operative assessment}

Patient selection was performed by a multidisciplinary team composed by a paediatric surgeon, a plastic surgeon, a specially trained phoniatrician and a speech therapist. The pre- and post-operative evaluations included: the clinical examination of the voice and the videonasopharyngoscopy. The perceptual evaluation of the voice was performed by the phoniatrician that analysed spontaneous speech, repetition of sentences and phonemes to assess resonance, audible air escape and turbulence, articulation defects. The hypernasality was assessed according to the Borel-Maisonny score [Table 2]. The videonasopharyngoscopy was performed by using a 
Table 1: Patient's details

\begin{tabular}{|c|c|c|c|c|c|c|c|c|}
\hline Patient & Age & Sex & VPI aetiology & VPP & Harvesting & $\begin{array}{l}\text { Injected } \\
\text { Amount }\end{array}$ & $\begin{array}{c}B M \\
\text { pre-operative }\end{array}$ & $\begin{array}{c}B M \\
\text { post-operative } \\
\end{array}$ \\
\hline 1 & 5 & Male & Primary & - & Thigh & 5 & $2 m$ & 1 \\
\hline 2 & 23 & Male & Cleft palate & - & Abdomen & 5 & $2 / 1$ & 1 \\
\hline 3 & 15 & Female & Primary & - & Abdomen & 10 & $2 b$ & $1 / 2$ \\
\hline 4 & 14 & Male & Adenotonsillectomy (Down syndrome) & - & Abdomen & 16 & $2 / 1$ & 1 \\
\hline 5 & 7 & Female & Primary & - & $\begin{array}{l}\text { Gluteal } \\
\text { region }\end{array}$ & 9 & $2 b$ & $1 / 2$ \\
\hline 6 & 6 & Male & Primary & - & $\begin{array}{l}\text { Gluteal } \\
\text { region }\end{array}$ & 5 & $2 / 1$ & 1 \\
\hline 7 & 7 & Female & Cleft palate & - & Abdomen & 8 & $2 b$ & 1 \\
\hline 8 & 10 & Female & Cleft palate (Pierre Robin syndrome) & - & Abdomen & 8 & $2 / 3$ & $1 / 2$ \\
\hline 9 & 20 & Male & Cleft lip and palate & - & Abdomen & 12 & $2 m$ & n.d. \\
\hline 10 & 4 & Male & Primary & - & Thigh & 5 & $2 b$ & $1 / 2$ \\
\hline 11 & 7 & Male & Cleft lip and palate & - & Abdomen & 8 & $2 m$ & $1 / 2$ \\
\hline 12 & 7 & Male & Cleft lip and palate & - & $\begin{array}{l}\text { Gluteal } \\
\text { region }\end{array}$ & 6 & $1 / 2$ & 1 \\
\hline 13 & 8 & Male & Cleft palate & + (pre) & Abdomen & 9 & $2 / 1$ & 1 \\
\hline 14 & 4 & Male & $\begin{array}{l}\text { Primary (congenital bilateral auris } \\
\text { atresia and speech delay) }\end{array}$ & $+($ post $)$ & Abdomen & 6 & $2 m$ & $2 m$ \\
\hline 15 & 11 & Female & Cleft palate & - & Thigh & 11 & $2 m$ & $1 / 2$ \\
\hline 16 & 9 & Male & Primary & - & $\begin{array}{l}\text { Gluteal } \\
\text { region }\end{array}$ & 5 & $2 / 1$ & $1 / 2$ \\
\hline 17 & 5 & Male & Cleft palate & - & $\begin{array}{l}\text { Gluteal } \\
\text { region }\end{array}$ & 5 & $2 b$ & $1 / 2$ \\
\hline 18 & 5 & Male & Primary & - & Abdomen & 4 & $2 m$ & $2 / 1$ \\
\hline 19 & 9 & Male & Primary & - & Abdomen & 5 & $2 m$ & $2 / 1$ \\
\hline 20 & 6 & Female & Primary & - & $\begin{array}{l}\text { Gluteal } \\
\text { region }\end{array}$ & 5 & $2 / 3$ & $2 b$ \\
\hline 21 & 16 & Female & Primary & - & Abdomen & 20 & $2 b$ & $2 / 1$ \\
\hline
\end{tabular}

flexible endoscope in all the patients. In younger patients, a small diameter $(<3 \mathrm{~mm})$ fibroscope was used.

The patients were asked to produce the phonemes 'a', 'i' and 's' with the aim to evaluate the velar mobility and the degree of velopharyngeal closure. The morphology of the pharynx, the presence of a submucosal cleft, adenoid rests and compensatory signs were evaluated. The post-operative evaluation was performed 6 months after surgery.

Moreover, we investigated the parental perception of the outcomes, their satisfaction rate and its impact on their child's speech and quality of life after surgery. We interviewed the parents of 19 treated patients. All the interviews were conducted through telephone by a trainee doctor of our team. The interview form is reported in Table 3. The interviews were performed between 6 and 60 months after surgery.

The Wilcoxon test allowed us to compare the pre- and post-treatment values of the Borel-Maisonny score and the intelligibility scores obtained with the interview.
Table 2: Borel-Maisonny score: Perceptive evaluation of hypernasality

\begin{tabular}{ll}
\hline Score & Definition \\
\hline 1 & Normal phonation, no nasal air emission \\
$1 / 2$ & $\begin{array}{l}\text { Good phonation, intermittent nasal air emission, good } \\
\text { intelligibility }\end{array}$ \\
$2 / 1$ & $\begin{array}{l}\text { Phonation with partially corrected nasal air emission } \\
2 b\end{array}$ \\
$\begin{array}{l}\text { Phonation with continuous nasal emission but good } \\
\text { intelligibility and no social discomfort }\end{array}$ \\
$2 \mathrm{~m}$ & $\begin{array}{l}\text { Phonation with continuous nasal emission and poor } \\
\text { intelligibility }\end{array}$ \\
$2 / 3$ & $\begin{array}{l}\text { Phonation with continuous nasal emission with } \\
\text { compensatory articulation, poor intelligibility }\end{array}$ \\
3 & $\begin{array}{l}\text { Continuous compensatory articulation and bad } \\
\text { intelligibility }\end{array}$ \\
\hline
\end{tabular}

The statistical analysis was performed using the software SOFA (version 1.4.6. www.sofastatistics.com, PatonSimpson \& Associates Ltd).

\section{Protocol of treatment}

On the basis of the results of the clinical examination of the voice and videonasopharyngoscopy, we followed this therapeutic approach. Patients with a velopharyngeal gap $<50 \%$ with a Borel-Maisonny score between $1 / 2$ and $2 / 3$ were considered candidates for lipofilling (only 
Table 3: Interview questions

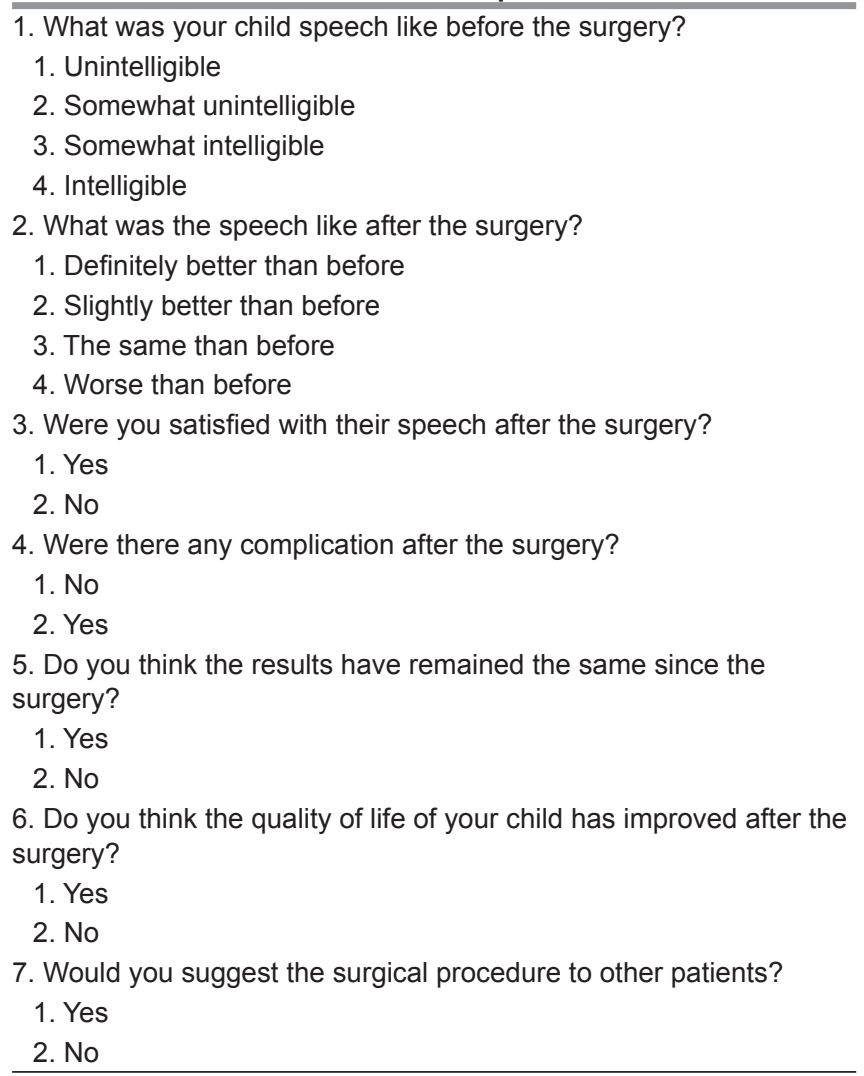

A lower score has been related to a higher level of satisfaction

after at least 1 year of speech therapy), whereas patients with velopharyngeal gap $>50 \%$ with continuous compensatory articulation and bad intelligibility of the speech (Borel-Maisonny score: 3) were candidates for pharyngoplasty. Borderline patients (Borel-Maisonny score: $2 \mathrm{~m}$ and 2/3) were informed before the surgery that there may be the possibility to perform more than one procedure of fat grafting or a pharyngoplasty, in case of unsatisfactory improvement.

\section{Surgical treatment}

The procedure was always performed under general anaesthesia. The fat was harvested from the abdomen or, in thin patients, from the thigh and from the gluteal area, after local infiltration with a $2 \%$ mepivacaine with epinephrine solution. A 2-mm skin incision was performed with an 11 blade and the anaesthetic solution was infiltrated using a multiple-hole infiltration cannula. A 3-mm, 3-hole blunt cannula connected to a $10 \mathrm{~mL}$ Luer-lock syringe was used to harvest the fat [Figure 1]. The harvested fat was always centrifuged at $3000 \mathrm{bpm}$ for $3 \mathrm{~min}$. The skin incision was sutured with a 5/0 nylon suture. An elastic dressing was placed in the donor area. The fat was transferred to a $2 \mathrm{~mL}$ Luer-lock syringe

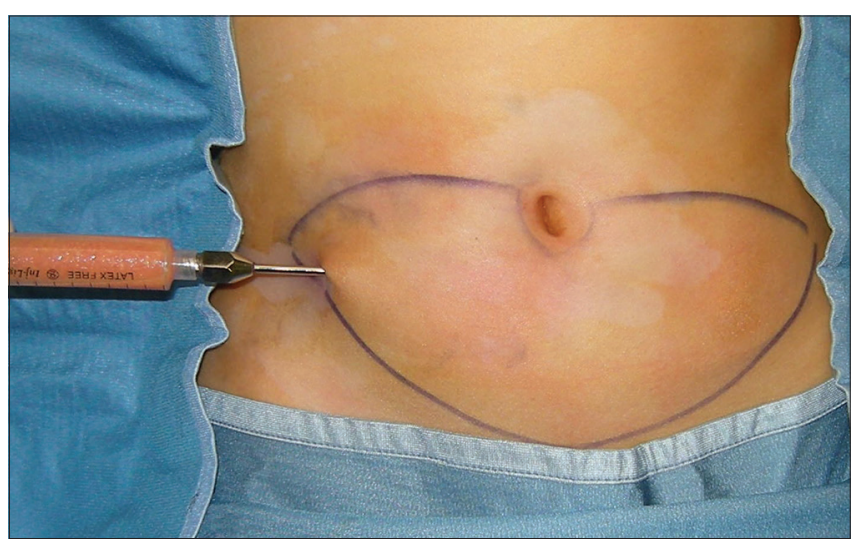

Figure 1: The fat harvesting site

using a specific Luer-lock adapter. With the patient in a supine position with the neck hyperextended, a Dingman mouth gag [Figure 2] was placed and the fat was injected into the posterior pharyngeal wall, superficial to the pre-vertebral fascia. Concerning the fat injection into the pharyngeal wall, we performed 1 incision in the midline of the posterior pharyngeal wall with an 11 blade and we placed the fat [Figure 3] using a slightly curved 20 -Gauge cannula, suturing the entry point with a $5 / 0$ absorbable suture. The level of the incision is represented by the anterior tubercle of the atlas at the level of the odontoid process. The cannula is advanced in a cranial and lateral direction and the fat is placed in the midline and paramedian. All the patients were discharged the day after the surgery. Prophylactic antibiotic treatment was administered in every case (amoxicillin/clavulanic acid based on the weight).

\section{RESULTS}

A total of 21 patients (14 males and 7 females), ages 4-23 affected by mild-to-moderate velopharyngeal insufficiency were included in the study. The mean injected fat volume was 7, $95 \mathrm{cc}$ (median $6 \mathrm{cc}$, min $4 \mathrm{cc}$, max $20 \mathrm{cc}$ and range $16 \mathrm{cc}$ ). The follow-up ranged from 6 to 60 months. One patient was lost at the follow-up. There were no major complications (bleeding, infection, obstructive sleep apnoea and embolism). After the surgery, most patients reported mild pain in the region of the neck and at the site of fat harvesting. In all these patients, the pain disappeared with intravenous administration of acetaminophen on the basis of the weight. There were no complications in the harvesting site and there were no complaints regarding the scars. The nasality was improved in all patients except in the case $n^{\circ} 14$ (injected fat volume: 6 cc). 


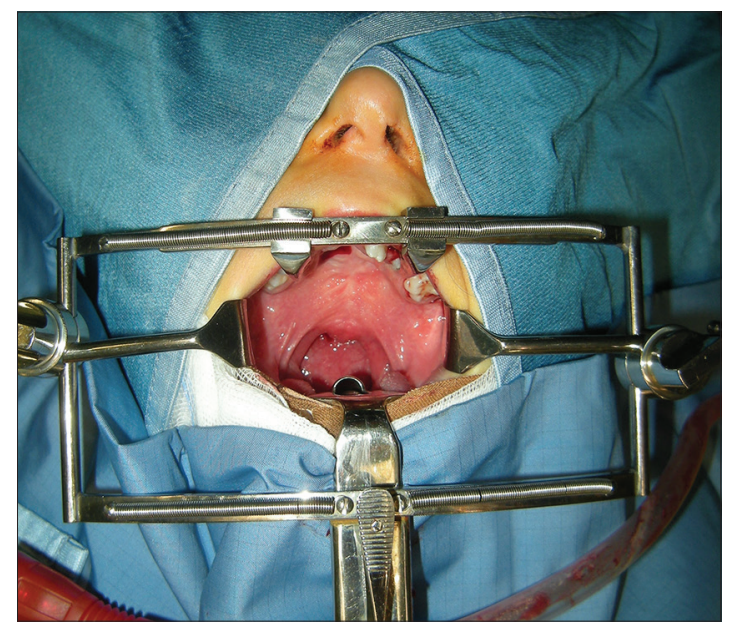

Figure 2: The operative field after placement of a Dingman mouth gag

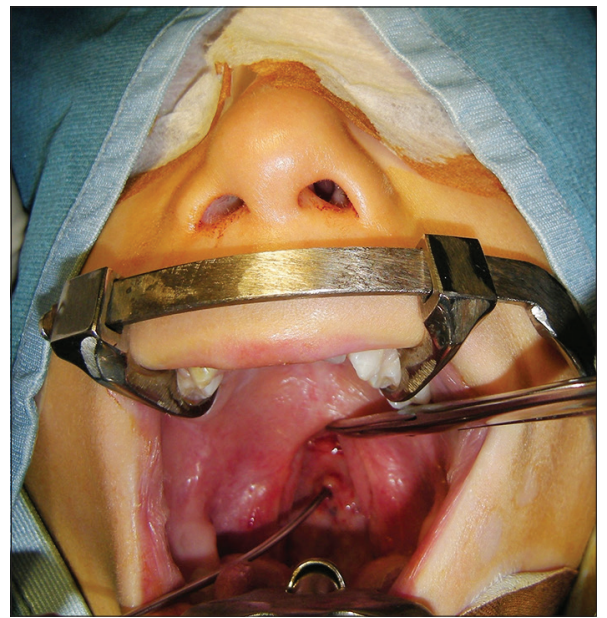

Figure 3: Fat injection into the posterior pharyngeal wall
The pre- and post-operative Borel-Maisonny scores are reported in Table 1. The Wilcoxon test showed that the improvement was statistically significant.

Regarding the phone interviews, a trainee doctor of our department contacted the parents of 19 patients (all the patients under 18 years old). He could not contact 2 over 18-year-old patients: the case 2 lost at the follow-up and the case 9 who did not answer. In 16 cases $(84,2 \%)$, the parents of the treated patients reported a high level of satisfaction with a general improvement of the intelligibility of speech and quality of life. In the case 16, the mother of the patient referred that, despite an initial improvement of the speech, the results did not remain the same after surgery. In the cases 4 and 14, the parents did not observe any improvement in the intelligibility after surgery.

Regarding the parental perception of the intelligibility before and after the surgery, the speech of the patients of this case series was somewhat unintelligible in 10 of 19 patients. After the surgery in these patients, the speech was intelligible in 3 patients and somewhat intelligible in 6 patients. In one patient, the speech remained somewhat unintelligible. In the other 9 patients, the speech was somewhat intelligible before surgery, intelligible after surgery in 7 patients and remained somewhat intelligible in 2 patients. In one case of these 9 patients (case 16), the intelligibility worsened about 2 months after surgery and the mother did not refer any improvement.

The interviews scores are reported in Table 4. The Wilcoxon test showed that there was a statistically significant improvement in the parental perception of the intelligibility from the pre-operative to the post-operative.

\section{DISCUSSION}

VPI can be defined as the inability of the soft palate to completely close the posterior wall of the pharynx during speech and/or swallowing. It manifests clinically as abnormal resonance, rhinolalia and/or hypernasality and occasionally nasal regurgitation, with the related psychological effects on the patients and their families. The goals of the augmentation of the posterior wall of the pharynx with the lipofilling are to improve voice resonance and correct nasal air escape by reducing the velopharyngeal gap. As reported in the literature,,$^{[1-8]}$ the lipofilling allows to create a neo-Passavant's pad improving the intelligibility of the speech in cases of mild-to-moderate VPI. This technique has been reported to have good results since the first published works of Dejonckere in 2001 ${ }^{[9]}$ and Bardot et al. in 2007. ${ }^{[10]}$

The patient selection is a critical step and a multidisciplinary pre-operative assessment is mandatory. In our department, patients are evaluated by a dedicated team composed by a paediatric surgeon, a plastic surgeon, a specially trained phoniatrician and a speech therapist. The pre-operative evaluation includes a complete physical examination, the perceptual speech assessment and the videonasopharyngoscopy.

A comprehensive physical examination is a requisite for all children with VPI to identify the presence of syndromic stigmata, craniofacial dysmorphisms and cardiac abnormalities. The head-and-neck examination 
Table 4: Interview scoring

\begin{tabular}{|c|c|c|c|c|c|c|c|c|c|c|}
\hline Patient & Age & Sex & Months after surgery & Question 1 & Question 2 & Question 3 & Question 4 & Question 5 & Question 6 & Question 7 \\
\hline 1 & 5 & Male & 60 & 3 & 1 & 1 & 1 & 1 & 1 & 1 \\
\hline 2 & 23 & Male & NA & - & - & - & - & - & - & - \\
\hline 3 & 15 & Female & 58 & 3 & 2 & 1 & 1 & 1 & 1 & 1 \\
\hline 4 & 14 & Male & 58 & 2 & 2 & 2 & 1 & 2 & 2 & 2 \\
\hline 5 & 7 & Female & 58 & 3 & 2 & 1 & 1 & 2 & 1 & 1 \\
\hline 6 & 6 & Male & 57 & 2 & 1 & 1 & 1 & 1 & 1 & 1 \\
\hline 7 & 7 & Female & 57 & 2 & 1 & 1 & 1 & 1 & 1 & 1 \\
\hline 8 & 10 & Female & 52 & 3 & 1 & 1 & 1 & 1 & 1 & 1 \\
\hline 9 & 20 & Male & NA & - & - & - & - & - & - & - \\
\hline 10 & 4 & Male & 48 & 2 & 1 & 1 & 1 & 1 & 1 & 1 \\
\hline 11 & 7 & Male & 44 & 3 & 2 & 1 & 1 & 1 & 1 & 1 \\
\hline 12 & 7 & Male & 44 & 2 & 1 & 1 & 1 & 1 & 1 & 1 \\
\hline 13 & 8 & Male & 37 & 2 & 1 & 1 & 1 & 1 & 1 & 1 \\
\hline 14 & 4 & Male & 31 & 3 & 3 & 2 & 1 & NA & 2 & 2 \\
\hline 15 & 11 & Female & 31 & 3 & 1 & 1 & 1 & 1 & 1 & 1 \\
\hline 16 & 9 & Male & 11 & 2 & 1 & 1 & 1 & 2 & 2 & 2 \\
\hline 17 & 5 & Male & 11 & 2 & 1 & 1 & 1 & 1 & 1 & 1 \\
\hline 18 & 5 & Male & 11 & 2 & 1 & 1 & 1 & 1 & 1 & 1 \\
\hline 19 & 9 & Male & 9 & 3 & 2 & 1 & 1 & 1 & 1 & 1 \\
\hline 20 & 6 & Female & 6 & 3 & 2 & 1 & 1 & 1 & 1 & 1 \\
\hline 21 & 16 & Female & 6 & 3 & 2 & 1 & 1 & 1 & 1 & 1 \\
\hline
\end{tabular}

includes an assessment of the middle-ear status. An oral examination is performed to identify the presence of a cleft and status of repair.

The perceptual speech assessment is considered the most reliable method of VPI ${ }^{[11]}$ diagnosis and serves as the basis for all instrumental evaluations.

Videonasopharyngoscopy is nowadays recognised as one of the recommended examinations for surgical planning ${ }^{[11]}$ of VPI. The other major tool used is the multiview videofluoroscopy but, as reported in the literature $^{[12]}$ and in the authors' clinical experience, videonasopharyngoscopy may be superior for assessing the degree of VPI. However, endoscopy is rarely possible in children under the age of 4 years, while videofluoroscopy can be carried out in very young patients. ${ }^{[13]}$

Fluoroscopy can also be useful when additional information is needed and in children who have limited cooperation for a functional endoscopic assessment.

The augmentation of the posterior pharyngeal wall is indicated in cases of mild-to-moderate VPI. The use of different materials has been described since 1900: vaseline, ${ }^{[14]}$ paraffin, teflon, ${ }^{[15]}$ silicone, ${ }^{[16]}$ proplast, ${ }^{[17]}$ collagen, ${ }^{[18]}$ autologous cartilage, ${ }^{[19]}$ mucosal and muscle flaps. ${ }^{[20 \mid}$ These techniques have been abandoned because of migration, extrusion and/or foreign body reaction. Nowadays, the autologous fat is widely used and can be considered the best filler available ${ }^{[21]}$ for the treatment of different pathologies also in paediatric patients. ${ }^{[22]}$ Lipofilling for the treatment of VPI has been proposed since 2001 and at our knowledge in the literature are present 13 published articles..$^{[1,10,23-25]}$ All the cited studies reported good results, and despite the potential major risks (obstructive sleep apnoea, fat embolism and/or injuries to the internal carotid artery), many authors insist on the safety of the procedure and on the possibility of its repetition in case of partial improvement.

Furthermore, according to some authors, the autologous fat grafting can also be proposed to patients with aberrant courses of internal carotid arteries, ${ }^{[26]}$ as can occur in the velocardiofacial syndrome. ${ }^{\mid 27]}$ As reported in the literature, ${ }^{[26]}$ about $5 \%$ of the population has internal carotid arteries aberrant course.

However, in this case series of patients, we did not observe any patient with this anatomic variation.

\section{Surgical technique}

Lipotransfer can be divided into four steps: infiltration, lipoaspiration, fat processing and injection. Different modifications of the original technique have been described in the last decades with the aim to preserve the fat viability. 


\section{Infiltration}

Lipoaspiration can be carried out after injecting a physiological solution. The standard ratio for infiltration is commonly $1 \mathrm{cc}$ infiltrated for $1 \mathrm{cc}$ of fat tissue removed. The amount of the needed fat in the treatment of VPI is generally small $(4-20 \mathrm{~mL}$ in our case series), so we generally use about $20 \mathrm{~mL}$ of a solution that contains mepivacaine to avoid post-operative pain and epinephrine to prevent bleeding.

\section{Lipoaspiration}

In this case series, the fat was harvested from the abdomen, from the inner thigh and knee, and no differences were found concerning the outcomes. As reported in the literature, at present, there is no evidence of a preferred donor site for fat viability. ${ }^{[28-30]}$ Regarding the lipoaspiration cannula and syringe, we used a $3 \mathrm{~mm}$, 3-hole blunt cannula connected to a $10 \mathrm{~mL}$ Luer-lock syringe. A smaller cannula diameter could affect the viability of the fat. ${ }^{[31,32]}$ Moreover, the negative pressure caused by aspiration is a critical factor in graft survival, ${ }^{[33]}$ therefore, pulling the plunger should be carried out with caution.

\section{Fat processing}

In this case series, we always centrifuged the harvested fat at $3000 \mathrm{bpm}$ for $3 \mathrm{~min}$ to separate and remove blood, cell debris and the oily layer according to the Coleman technique. Recently, we have started to use new protocols to purify the fat by decantation and centrifugation and multiple washing with the aim to optimise the technique on the basis of recently published researches. ${ }^{[34,35]}$ No differences in the short-term outcomes were found, but we need more data and long-term follow-up to make conclusions.

\section{Injection}

The injection technique is of paramount importance and should be performed very carefully with the aim to limit the risk of complications such as embolism ${ }^{[7,36]}$ and obstructive sleep apnoea. ${ }^{[37]}$ The patient should be placed supine and the ventilation tube should pass through the mouth. A Dingman mouth gag depresses the tongue and allows to have a good operative field. It is important to maintain the patient's neck hyperextended during the fat injection, with the aim to reduce the risk of vascular injuries by making more straight and lateral the course of the internal carotids arteries. The assistance of an endoscope can be useful to better visualise the operating field. ${ }^{[7]}$ It is also essential to pull the plunger back of the syringe before fat injection, in order to avoid fat embolism.

Regarding the outcomes, we admit that this study presents some limitations. First of all, we injected a variable amount of fat only in the posterior pharyngeal wall. Moreover, we did not perform any instrumental evaluation to determine the fat resorption that could be related with the evolution of the functional results. However, according to the results published in the literature, in our case series of patients affected by mild-to-moderate VPI treated with lipofilling, we have reported a general improvement of the Borel-Maisonny score and intelligibility of the speech with a clinical reduction of the air escape. In patient $n^{\circ}$ 14 (injected fat volume: $6 \mathrm{cc}$ ), we did not observe any improvement probably because of the severity of the VPI and co-morbidity (congenital aural atresia with speech delay). He had pharyngoplasty 14 months after lipofilling. In this study, the mean injected fat volume was $7.95 \mathrm{cc}$ (median $6 \mathrm{cc}$, min $4 \mathrm{cc}$, max $20 \mathrm{cc}$, range $16 \mathrm{cc}$ ). The volume of injected fat varied on the basis of the gap. In the case 21 (16-year-old patient), we injected 20 cc of fat reporting a partial improvement of the post-operative Borel-Maisonny score. However, a big amount of fat in the same spot may not survive and it could be counterproductive.

\section{Injection site}

Based on the literature data, different sites of fat injection are described. In 2007, Bardot et al. performed the injection under the mucosa of the lateral and posterior pharyngeal wall. ${ }^{[10]}$ In 2009, Leuchter et al. identified the main injection site in the middle of the posterior pharyngeal wall. ${ }^{[2]}$ In 2011, Teixera et al. reported a particular case of obstructive sleep apnoea after fat injection in the soft palate. After the second fat injection in a paediatric patient, they had to perform a fat debulking procedure. Other authors in 2011 published their experience of injection in the velum in the posterior and in the lateral pharyngeal walls without

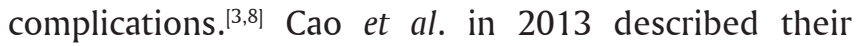
technique of injection only in the posterior pharyngeal wall. ${ }^{[4]}$ Filip et al. in 2013 reported the injection of the velum, palatopharyngeal arches and posterior pharyngeal wall..$^{[5]}$ In 2015, Boneti et al. described their modality of injection in the soft palate alone. ${ }^{[6]}$ In the same year, Piotet presented a case series of 22 patients with cleft palate treated with lipofilling performed in the posterior pharyngeal wall through the soft palate. Mazzola et al. clarified the level of the fat placement into 
the submucosal plane of the posterior pharyngeal wall performing two stab incisions respecting the midline. ${ }^{[7]}$ Since 2012, when we started to treat VPI with lipofilling we have been injecting the fat only into the posterior pharyngeal wall (in multiple tunnels in the midline and paramedian), performing one incision in the midline with the aim to reduce the risk of major complications such as obstructive sleep apnoea and embolism as highlighted by Bishop et al. ${ }^{[25]}$ in their review. This could explain the poor results obtained in some patients of this case series. Hence, we have recently started to inject the fat into the velum with the aim to soften scars contractures in cases of secondary VPI (after cleft repair and after VPP) with preliminary good results.

\section{Fat resorption}

The main drawback of the lipofilling is fat resorption. The literature are reported fat resorption rates from $30 \%$ to $80 \%$ for clinical evaluations and from $50 \%$ to $90 \%$ for the experimental evaluation. ${ }^{[38]}$ However, in patients affected by VPI, an overcorrection could be counterproductive and could cause obstructive sleep apnoea. ${ }^{[37]}$ The role of lipofilling in the VPI treatment is to reduce the velopharyngeal gap (a small amount of fat is generally required) and to soften scar contractures after cleft palate repair, facilitating the approximation of the velum to the posterior pharyngeal wall. ${ }^{[7]}$ Recent studies have confirmed the important role of the stromal vascular fraction of the injected fat in the angiogenesis and regeneration for fibrotic scar treatment. ${ }^{[39]}$

In the author's experience and according to the literature, ${ }^{[10]}$ the outcomes after the fat injection can be considered stable after three months. ${ }^{[38]}$ In this case series, all the patients underwent one procedure of fat injection. As reported in the literature, a further procedure can be performed in cases of partial improvement and/or worsening of the speech intelligibility during children growing up. In the presented case series, in three patients, the results have not remained the same since the surgery probably because of fat resorption. It is difficult to detect the survival of the transplanted fat, especially in young patients. Cao et al. in their recent work performed a pre- and post-operative magnetic resonance imaging (MRI) in a case series of 11 patients, reporting good survival fat rates. ${ }^{[4]}$ Good outcomes were reported also by Filip et al. in their case series of patients because they did not find a statistical correlation between the change of the velopharyngeal distance or the velopharyngeal gap area and the change of the speech parameters. ${ }^{[5]}$ We have recently started to perform pre- and post-operative MRI to obtain more data about the survival of the transplanted fat, however, in this case series, we cannot produce any data. Moreover, pre-operative MRI could also be useful to identify more precisely the injection site.

\section{Parent perception survey}

In the authors' opinion, the role of parents is very significant in the management of VPI in paediatric patients. Despite the possible bias due to the modality of the interview (performed by a trainee doctor of our team), our research allows us to conclude that the lipofilling of the pharyngeal wall is well tolerated by children and accepted by their families. On the basis of the phone interviews, the parents' perception of the procedure is satisfying in 16 cases. In these 16 cases, the interviewed parents consider their children's quality of life (including eating, drinking, friendship, confidence and social interactions) improved after the treatment and in 15 cases, in their opinion, the lipofilling has provided long-term successful outcomes. In 16 cases, the children parents would suggest the treatment with lipofilling to other patients affected by VPI. This data in our opinion are very important, especially when we have to explain to parents the surgical alternatives and the possible necessity of more than one surgical session. We reported the interview results on the information model that patients and/or parents have to read before signing the informed consent.

\section{CONCLUSIONS}

Despite the possible provisional nature of the outcomes, due to the reported limitations of this study, the augmentation of the posterior pharyngeal wall in addition to speech therapy improved the Borel-Maisonny score and the intelligibility of this case series of patients. This technique allowed us to avoid major surgical procedures that would modify the anatomy of the velopharyngeal port. However, prospective comparative studies or randomised controlled trials could be useful to compare fat grafting with VPP techniques, with the aim to clarify indications and to define a specific treatment protocol.

\section{Declaration of patient consent}

The authors certify that they have obtained all appropriate patient consent forms. In the form the patient(s) has/have given his/her/their consent for his/ her/their images and other clinical information to be 
reported in the journal. The patients understand that their names and initials will not be published and due efforts will be made to conceal their identity, but anonymity cannot be guaranteed.

\section{Financial support and sponsorship}

Nil.

\section{Conflicts of interest}

There are no conflicts of interest.

\section{REFERENCES}

1. Piotet E, Beguin C, Broome M, Iglesias K, Olivier F, Leuchter I, et al. Rhinopharyngeal autologous fat injection for treatment of velopharyngeal insufficiency in patients with cleft palate. Eur Arch Otorhinolaryngol 2015;272:1277-85.

2. Leuchter I, Schweizer V, Hohlfeld J, Pasche P. Treatment of velopharyngeal insufficiency by autologous fat injection. Eur Arch Otorhinolaryngol 2010;267:977-83.

3. Leboulanger N, Blanchard M, Denoyelle F, Glynn F, Charrier JB, Roger $\mathrm{G}$, et al. Autologous fat transfer in velopharyngeal insufficiency: Indications and results of a 25 procedures series. Int J Pediatr Otorhinolaryngol 2011;75:1404-7.

4. Cao Y, Ma T, Wu D, Yin N, Zhao Z. Autologous fat injection combined with palatoplasty and pharyngoplasty for velopharyngeal insufficiency and cleft palate: Preliminary experience. Otolaryngol Head Neck Surg 2013;149:284-91.

5. Filip C, Matzen M, Aagenæs I, Aukner R, Kjøll L, Høgevold HE, et al. Autologous fat transplantation to the velopharynx for treating persistent velopharyngeal insufficiency of mild degree secondary to overt or submucous cleft palate. J Plast Reconstr Aesthet Surg 2013;66:337-44.

6. Boneti C, Ray PD, Macklem EB, Kohanzadeh S, de la Torre J, Grant JH, et al. Effectiveness and safety of autologous fat grafting to the soft palate alone. Ann Plast Surg 2015;74 Suppl 4:S190-2.

7. Mazzola RF, Cantarella G, Mazzola IC. Regenerative approach to velopharyngeal incompetence with fat grafting. Clin Plast Surg 2015;42:365-74, ix.

8. Cantarella G, Mazzola RF, Mantovani M, Baracca G, Pignataro L. Treatment of velopharyngeal insufficiency by pharyngeal and velar fat injections. Otolaryngol Head Neck Surg 2011;145:401-3.

9. Dejonckere $\mathrm{PH}$, van Wijngaarden HA. Retropharyngeal autologous fat transplantation for congenital short palate: A nasometric assessment of functional results. Ann Otol Rhinol Laryngol 2001;110:168-72.

10. Bardot J, Salazard B, Casanova D, Pech C, Magalon G. Velopharyngeal sequels in labial-alveolar-velopalatine clefts. Pharyngoplasty by pharynx Lipostructure ${ }^{\circledR}$. Rev Stomatol Chir Maxillofac 2007;108:352-6.

11. Conley SF, Gosain AK, Marks SM, Larson DL. Identification and assessment of velopharyngeal inadequacy. Am J Otolaryngol 1997;18:38-46.

12. Lam DJ, Starr JR, Perkins JA, Lewis CW, Eblen LE, Dunlap J, et al. A comparison of nasendoscopy and multiview videofluoroscopy in assessing velopharyngeal insufficiency. Otolaryngol Head Neck Surg 2006;134:394-402.

13. Sommerlad BC. Evaluation of VPI-assessment with videofluoroscopy and nasoendoscopy. $\mathrm{Br} J$ Plast Surg 2005;58:932-3.

14. Gersuny R. The classic reprint. Concerning a subcutaneous prosthesis: Robert Gersuny. (Uber eine subcutane Prothese. Zeitschrift f. Heilkunde Wien u Leipzig 21:199, 1900.). Translated from the German by Miss Rita Euerle. Plast Reconstr Surg 1980;65:525-7. Available from: http://www.ncbi.nlm.nih.gov/ pubmed/6987692.

15. Bluestone CD, Musgrave RH, McWilliams BJ, Crozier PA. Teflon injection pharyngoplasty. Cleft Palate J 1968;5:19-22.

16. Brauer RO. Retropharyngeal implantation of silicone gel pillows for velopharyngeal incompetence. Plast Reconstr Surg 1973;51:254-62.

17. Wolford LM, Oelschlaeger M, Deal R. Proplast as a pharyngeal wall implant to correct velopharyngeal insufficiency. Cleft Palate J 1989;26:119-26.

18. Remacle M, Bertrand B, Eloy P, Marbaix E. The use of injectable collagen to correct velopharyngeal insufficiency. Laryngoscope 1990;100:269-74.

19. Trigos I, Ysunza A, Gonzalez A, Vazquez MC. Surgical treatment of borderline velopharyngeal insufficiency using homologous cartilage implantation with videonasopharyngoscopic monitoring. Cleft Palate J 1988;25:167-70

20. Hynes W. Pharyngoplasty by muscle transplantation. Br J Plast Surg 1950;3:128-35.

21. Coleman SR. Structural fat grafts: The ideal filler? Clin Plast Surg 2001;28:111-9.

22. Moratalla JareñoT, GonzálezAlonso V, LópezBlancoE, Domenèch Tárrega A, Carazo Palacios E, Gutiérrez Ontalvillas $P$, et al. Use of lipofilling in pediatric patients. Cir Pediatr 2013;26:189-94.

23. Dinsever Eliküçük Ç, Kulak Kayıkcı ME, Esen Aydını $F$, Çalış M, Özgür FF, Öztürk M, et al. Investigation of the speech results of posterior pharyngeal wall augmentation with fat grafting for treatment of velopharyngeal insufficiency. J Craniomaxillofac Surg 2017;45:891-6.

24. Guerrerosantos J, Chicas M, Rivera H. Palatopharyngeal lipoinjection: An advantageous method in velopharyngeal incompetence. Plast Reconstr Surg 2004;113:776-7.

25. Bishop A, Hong P, Bezuhly M. Autologous fat grafting for the treatment of velopharyngeal insufficiency: State of the art. J Plast Reconstr Aesthet Surg 2014;67:1-8.

26. Bois $E$, Celerier $C$, Belhous $K$, Maulet $M$, Leboulanger $N$, Garabedian N, et al. Velopharyngeal insufficiency managed by autologous fat grafting in patients with aberrant courses of internal carotid arteries. Int J Pediatr Otorhinolaryngol 2017;96:135-9.

27. Baek RM, Koo YT, Kim SJ, Kim JH, Kim JY, Kim BK, et al. Internal carotid artery variations in velocardiofacial syndrome patients and its implications for surgery. Plast Reconstr Surg 2013;132:806e-810e

28. Li K, Gao J, Zhang Z, Li J, Cha P, Liao Y, et al. Selection of donor site for fat grafting and cell isolation. Aesthetic Plast Surg 2013;37:153-8.

29. Rohrich RJ, Sorokin ES, Brown SA. In search of improved fat transfer viability: A quantitative analysis of the role of centrifugation and harvest site. Plast Reconstr Surg 2004;113:391-5.

30. Hivernaud V, Lefourn B, Guicheux J, Weiss P, Festy F, Girard AC, et al. Autologous fat grafting in the breast: Critical points and technique improvements. Aesthetic Plast Surg 2015;39:547-61.

31. Gause $T M 2^{\text {nd }}$, Kling RE, Sivak WN, Marra KG, Rubin JP, Kokai LE, et al. Particle size in fat graft retention: A review on the impact of harvesting technique in lipofilling surgical outcomes. Adipocyte 2014;3:273-9.

32. Erdim M, Tezel E, Numanoglu A, Sav A. The effects of the size of liposuction cannula on adipocyte survival and the optimum temperature for fat graft storage: An experimental study. J Plast Reconstr Aesthet Surg 2009;62:1210-4. 
33. Tambasco D, Arena V, Grussu F, Cervelli D. Adipocyte damage in relation to different pressures generated during manual lipoaspiration with a syringe. Plast Reconstr Surg 2013;131:645e-6e.

34. Girard AC, Mirbeau S, Gence L, Hivernaud V, Delarue P, Hulard $\mathrm{O}$, et al. Effect of washes and centrifugation on the efficacy of lipofilling with or without local anesthetic. Plast Reconstr Surg Glob Open 2015;3:e496.

35. Hoareau L, Bencharif K, Girard AC, Gence L, Delarue P, Hulard $\mathrm{O}$, et al. Effect of centrifugation and washing on adipose graft viability: A new method to improve graft efficiency. J Plast Reconstr Aesthet Surg 2013;66:712-9.

36. Filip C. Response re: Autologous fat grafting for the treatment of velopharyngeal insufficiency: State of the art. J Plast Reconstr Aesthetic Surg 2014;67:1155-6.

37. Teixeira RP, Reid JA, Greensmith A. Fatty hypertrophy cause obstructive sleep apnea after fat injection for velopharyngeal incompetence. Cleft Palate Craniofac J 2011;48:473-7.

38. Ho Quoc C, Taupin T, Guérin N, Delay E. Volumetric evaluation of fat resorption after breast lipofilling. Ann Chir Plast Esthet 2015;60:495-9.

39. Spiekman $M$, van Dongen JA, Willemsen JC, Hoppe DL, van der Lei B, Harmsen MC, et al. The power of fat and its adipose-derived stromal cells: Emerging concepts for fibrotic scar treatment. J Tissue Eng Regen Med 2017;11:3220-35. 